\title{
Feedstock recycling of waste polymers by thermal cracking in molten metal: thermodynamic analysis
}

\author{
Marek Stelmachowski
}

Received: 31 October 2011/ Accepted: 11 March 2013/Published online: 7 August 2013

(C) The Author(s) 2013. This article is published with open access at Springerlink.com

\begin{abstract}
Waste plastics contribute to serious environmental and social problems, such as the loss of natural resources, environmental pollution, and depletion of landfill space, but they also create demands on the environmentally-oriented part of the society. Feedstock recycling of scrap polymers by thermal and chemical methods is well known and environmentally accepted. The paper presents the results of thermodynamic analysis of the conversion of polyolefins in a fuel-like mixture of hydrocarbons using thermal cracking in a new type of tubular reactor with molten metal. Evaluation of the efficiency of the process was based on exergy calculations. Calculated exergy efficiency was ca. $79.5 \%$. It means that feedstock recycling of waste is better from an energetic and environmental point of view than other processes, particularly incineration.
\end{abstract}

Keywords Plastic wastes - Thermodynamic analysis · Exergy · Pyrolysis · Thermal cracking

\section{Introduction}

It is hard to estimate global production of plastics (excluding fibers) especially when available data vary [1, $2]$. The consumption of plastics per capita differs across the world and ranges from 5 to $150 \mathrm{~kg} /$ person/year. Therefore, the amount of waste plastics is increasing by 6.6-12\% each year depending on the country. In Poland, plastics consumption per capita was $45 \mathrm{~kg}$ in 2007 [3].

\section{Stelmachowski ( $\square$ )}

Department of Safety Engineering, Faculty of Process and Environmental Engineering, Technical University of Lodz, 90-924, Lodz, Poland

e-mail: marek.stelmachowski@p.lodz.pl
Scrap plastics represent only 7-9 \% of the total waste in terms of mass, but they account for ca. $30 \%$ in terms of volume. Polyethylene (PE), polypropylene (PP), and polystyrene (PS) represent ca. $70 \%$ of plastic waste. The largest amount of polymer waste is dumped in landfills (40-90\%) or incinerated, with no attempt to recycle using chemical recycling or thermal degradation techniques [1, 4-7].

Reducing the amount of plastic waste at the source, which is the most favorable method among sustainable development strategies, is very difficult. In the near future, disposal of organic waste and plastics in landfills will be almost impossible because of regulations, high cost, and increasing environmental awareness of the public. Mechanical recycling, which is probably the best way of reclaiming plastics, includes processes that involve sorting, shredding or melting and re-granulation. It may be applied only to clean plastics and plastics of the same type. Energy recovery by incineration is criticized because of the absence of raw material recovery, low thermodynamic efficiency, possible emission of toxic gaseous compounds and the necessity to purify flue gases.

Feedstock recycling of scrap polymers by thermal and chemical degradation is well known and environmentally accepted. Figure 1 shows that it enables one to recover raw materials (and primary energy) from waste and applied processes that are identical or similar to those of energy carriers production. Feedstock recycling has come a long way from its inception as a scientific idea to industrial application. At least, 30-40 commercial technologies are available to thermally degrade post-consumer plastics using pyrolysis or catalytic cracking and convert them in a fuel-like-mixture of hydrocarbons [4, 6]. However, industrial installations are rare. In Germany, Poland and other European countries, only about $2-3 \%$ of waste polymeric 


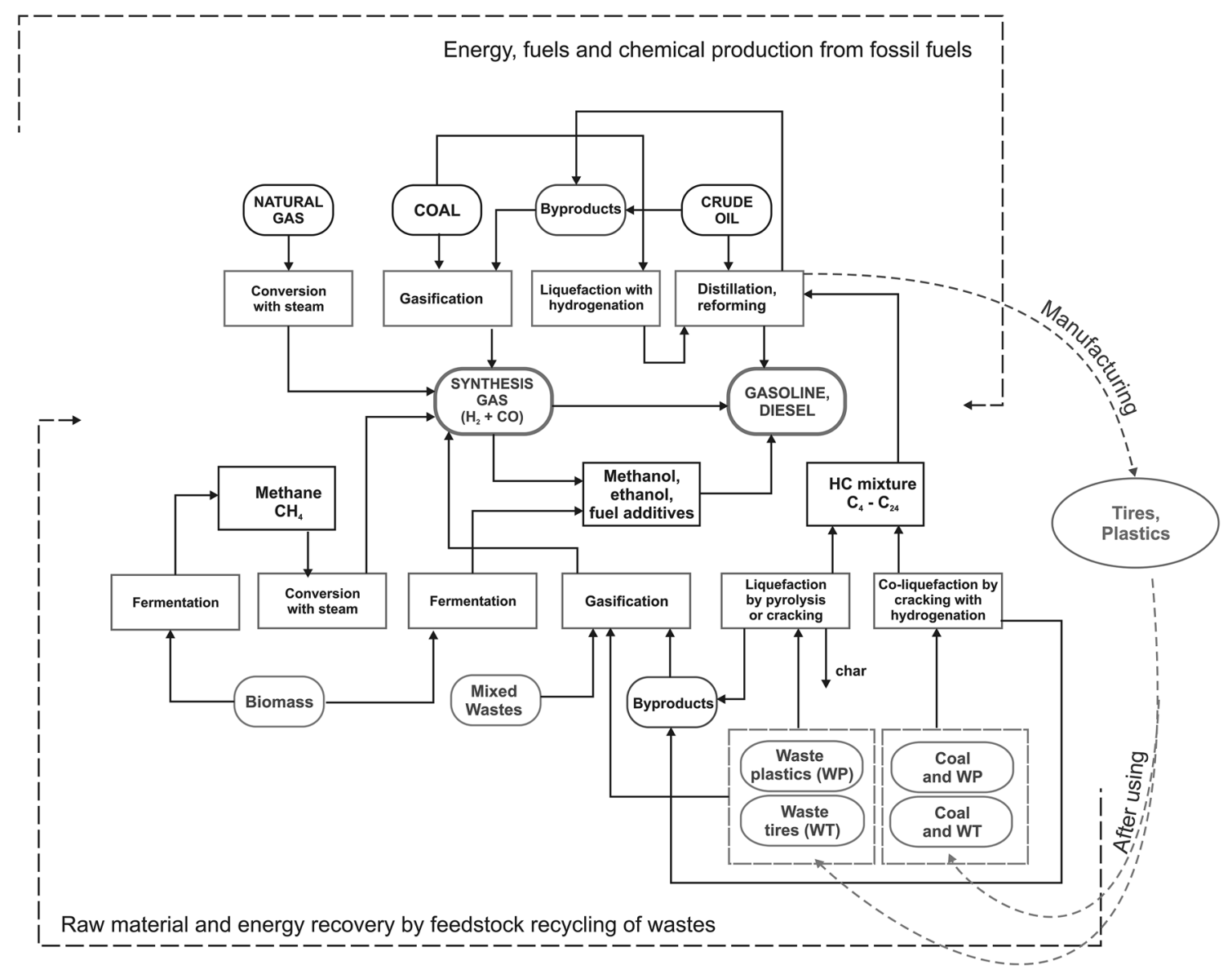

Fig. 1 Raw materials and primary energy recovery from wastes

materials (excluding fibers) are utilized using pyrolysis, cracking or chemolysis. It means that the proposed processes are imperfect, their profitability is poor and environmental policy pursued in European countries does not promote these methods of utilization of waste polymers. Unfavorable attitude to feedstock recycling of waste polymers is mostly due to high investment cost, the necessity of frequent cleaning of the reactor, cost of catalysts and other economic circumstances, e.g., taxes.

\section{Method}

Generally, the conversion of waste to raw product by feedstock recycling is often based on thermal and catalytic cracking or pyrolysis. Reactors used for this purpose may be of very different construction $[4,6]$. The yields of liquid, gaseous and solid products depend on many parameters such as: the composition of the mixture, temperature, type of catalyst, residence time in the reactor, type of the reactor and type of the process (multi- or single stage, in gas or liquid phase with a solvent), heating rate, etc. Typical thermal pyrolysis may have some disadvantages. One of them, and probably the most important one, is cooking that may occur at the walls of reactors. It decreases the yield of liquid product, makes heat transfer difficult, and requires frequent cleaning of the reactor. The catalytic process has also got its disadvantages. Though catalysts may decrease the temperature of the process, change the selectivity and the composition of products, they produce more gas products, catalysts are quickly deactivated and their recovery and regeneration are not easy and may increase the cost of the process. Many researchers and inventors propose fluidized-bed reactors due to their advantages. Difficulties with the mixing of wastes, removing the coke, regeneration of the catalyst and heat transfer resistance may be solved and/or reduced in an easy way. However, due to investment cost involved, fluidized bed reactors may be profitable probably only in large industrial-scale installations.

New technologies (and reactors) should represent at least two the following features:

- Low operating and investment cost because plastics, waste plastics, and products of their degradation are not expensive and the conversion must be profitable for investors. 
- The process should be carried out without catalysts due to difficulties and cost of their recovery.

Various types of unconventional technologies have also been investigated and developed. A new KDV-process has been proposed by Dr. Ch. Koch at the beginning of the $21 \mathrm{st}$ century based on the reactor of a new type. Unfortunately, no scientific description of the process was published in the literature. Technology, proposed by Alchemix Corporation [7], is based on the conversion of organic wastes to hydrogen on the surface of molten metal-iron with the addition of tin. Molten salt oxidation - thermal treatment process to destroy organic wastes-is performed by injecting wastes beneath the surface of the bed of molten carbonate salts at $900-950{ }^{\circ} \mathrm{C}$. Catalytic oxidation leads to inorganic products $\left(\mathrm{CO}_{2}, \mathrm{H}_{2} \mathrm{O}, \mathrm{NO}_{x}, \mathrm{SO}_{2}\right.$, etc.) without recycling organic or inorganic products (hydrocarbons, hydrogen, methane, etc.) and energy [8]. The technology of waste polymers conversion (into a mixture of hydrocarbons) based on their thermal degradation beneath or on the surface of the alloy of molten metal (tin, lead and bismuth) [9] called sometimes the "Clementi Process", is carried out below $600{ }^{\circ} \mathrm{C}$ (often between 350 and $550{ }^{\circ} \mathrm{C}$ ).

A new type of vertical tubular reactor with a molten metal (lead, tin or their alloy) bed is proposed here to convert waste plastics into a valuable product, namely, a fuel-like mixture of hydrocarbons [10]. The process is carried out at temperatures between 380 and $420{ }^{\circ} \mathrm{C}$. Its basic product is a mixture of hydrocarbons (i.e., paraffins and olefins $\mathrm{C}_{4}-\mathrm{C}_{24}$ ), and heavy metal content is low $[11,12]$. It is quite different from reactors patented until now $[13,14]$.

The description of laboratory set-up, experimental procedures and the results of thermal degradation of waste polyethylene and polypropylene in a laboratory setup can be found in the previous study [11]. A summary of the obtained results is given below. A basic profile of the runs is presented in Table 1. The composition of average liquid and gas products for selected experiments is shown in Table 2. The yields of gaseous and liquid products and their composition indicate that the proposed reactor and method of scrap polyolefin degradation meet all demands of a profitable technology. Over $90 \%$ of waste polyolefins may be converted into a liquid product. Three basic fractions in the liquid product are usually distinguished for polymer degradation by pyrolysis or cracking: light ("gasoline"; $\mathrm{C}_{4} \div \mathrm{C}_{10}$ ), medium ("diesel" $\mathrm{C}_{11} \div \mathrm{C}_{16}$ ); and heavy ("light waxes" $\mathrm{C}_{17} \div \mathrm{C}_{24}$ ). Figure 2 presents the content of these fractions in liquid hydrocarbon mixtures obtained in experiments. No solid product (i.e., coke) was obtained in laboratory experiments for the degradation of pure plastics. However, impurities that are usually present in genuine waste of polymers may cause cooking, and a small amount of solid product consisting of mineral
Table 1 Basic profile of performed experiments

\begin{tabular}{lll}
\hline Polymer & HDPE & PP \\
\hline Temperature of the process $\left({ }^{\circ} \mathrm{C}\right)$ & $408-423$ & $362-417$ \\
Yield of the liquid product $(\mathrm{wt} \%)$ & $92-94$ & $96-98$ \\
Yield of the gas product $(\mathrm{wt} \%)$ & $6-8$ & $2-4.5$ \\
Yield of solid product $(\mathrm{wt} \%)$ & 0 & \\
\hline
\end{tabular}

impurities and coke may be obtained during the conversion of this type of waste. The highest experimental reaction rate of PE degradation was $2500-3500 \mathrm{~kg} / \mathrm{h} \mathrm{m}^{3}$ and of PP between 3600 and $4400 \mathrm{~kg} / \mathrm{h} \mathrm{m}^{3}$.

\section{Methodology of the estimation of exergy efficiency}

The first law of thermodynamics states that for every process, no energy can dissipate or be generated; the second law says that the quality of energy decreases. This quality, expressed as "useful energy", is called exergy. Exergy is the maximum amount of work that can be obtained from a material, taking into account the condition of the surrounding environment $[15,16]$. The loss of exergy is linearly related to the entropy generated in the process. Every product is useful, and wastes can be seen as potential resources as long as it has got exergy content. To evaluate energy efficiency of a process and to assess its impact upon the environment, we can use several environmental indicators. However, it seems that indicators based on thermodynamic considerations connected with exergy, can illustrate whether a development is the most sustainable. Basic principles of the methodology used to assess the impact of industrial processes on the environment and their energetic efficiencies were discussed in many articles $[15,17]$.

A Grassmann diagram for exergy flow and exergy efficiency assessment is presented in Fig. 3 [18]. According to Sciubba and Szargut [17, 18], exergy balance may be described as (disregarding work, exergy of construction materials, capital and human work):

$B_{\mathrm{D}}+\sum B_{\mathrm{ZRQ}}=\Delta B_{\mathrm{U}}+B_{\mathrm{UZ}}+L_{\mathrm{U}}+\delta B_{\mathrm{W}}+\delta B_{\mathrm{Z}}$,

where $B_{\mathrm{D}}$, denotes exergy stream of raw materials; $B_{\mathrm{ZRQ}}$, exergy stream of external heat source; $\Delta B_{\mathrm{U}}$, increase in exergy of the system; $B_{\mathrm{UZ}}$, exergy stream of products; $L_{\mathrm{U}}$, work, $\delta B_{\mathrm{W}}, \delta B_{\mathrm{Z}}$, exergy losses (internal and external).

Under such assumptions, direct exergy efficiency can be presented as:

$\eta_{B}=\frac{B_{\mathrm{UZ}}+L_{\mathrm{U}}}{B_{\mathrm{D}}+\Delta B_{\mathrm{ZRQ}}}$.

This type of analysis may be used also to evaluate methods of waste recycling. We can optimize the 
Table 2 Average composition of liquid and gas products for selected experiments

\begin{tabular}{|c|c|c|c|c|c|c|c|}
\hline \multirow[t]{4}{*}{ Carbon number of the group of isomers } & \multicolumn{7}{|c|}{ No. of the experiment } \\
\hline & & & 3 & 4 & 5 & 6 & 7 \\
\hline & \multicolumn{7}{|c|}{ Type of the polymer } \\
\hline & $\mathrm{PE}$ & $\mathrm{PE}$ & $\mathrm{PE}$ & PE & $\mathrm{PP}$ & PP & $\mathrm{PP}$ \\
\hline \multicolumn{8}{|c|}{ Mol fraction of the sum of isomers in the group in the liquid product } \\
\hline 4 & 0.0214 & 0.0574 & 0.0598 & 0.0659 & 0.1165 & 0.2331 & 0.0971 \\
\hline 5 & 0.0691 & 0.0902 & 0.0791 & 0.0747 & 0.1049 & 0.0327 & 0.1231 \\
\hline 6 & 0.0876 & 0.0816 & 0.0980 & 0.1036 & 0.0448 & 0.0422 & 0.0294 \\
\hline 7 & 0.0859 & 0.0770 & 0.0814 & 0.0849 & 0.2799 & 0.2490 & 0.0372 \\
\hline 8 & 0.0758 & 0.0694 & 0.0759 & 0.0714 & 0.0446 & 0.0463 & 0.2847 \\
\hline 9 & 0.0789 & 0.0695 & 0.0676 & 0.0674 & 0.0316 & 0.0272 & 0.0360 \\
\hline 10 & 0.0687 & 0.0624 & 0.0596 & 0.0604 & 0.0620 & 0.0718 & 0.0661 \\
\hline 11 & 0.0612 & 0.0582 & 0.0566 & 0.0600 & 0.0333 & 0.0234 & 0.0389 \\
\hline 12 & 0.0615 & 0.0523 & 0.0500 & 0.0545 & 0.1027 & 0.1033 & 0.1087 \\
\hline 13 & 0.0544 & 0.0526 & 0.0560 & 0.0580 & 0.0186 & 0.0154 & 0.0269 \\
\hline 14 & 0.0541 & 0.0544 & 0.0493 & 0.0523 & 0.0257 & 0.0151 & 0.0405 \\
\hline 15 & 0.0539 & 0.0505 & 0.0487 & 0.0530 & 0.0325 & 0.0406 & 0.0154 \\
\hline 16 & 0.0505 & 0.0453 & 0.0489 & 0.0458 & 0.0116 & 0.0093 & 0.0034 \\
\hline 17 & 0.0488 & 0.0516 & 0.0539 & 0.0467 & 0.0439 & 0.0484 & 0.0538 \\
\hline 18 & 0.0450 & 0.0365 & 0.0351 & 0.0334 & 0.0064 & 0.0050 & 0.0065 \\
\hline 19 & 0.0309 & 0.0308 & 0.0303 & 0.0287 & 0.0224 & 0.0115 & 0.0167 \\
\hline 20 & 0.0169 & 0.0195 & 0.0208 & 0.0228 & 0.0050 & 0.0110 & 0.0117 \\
\hline 21 & 0.0123 & 0.0150 & 0.0134 & 0.0070 & 0.0068 & 0.0052 & 0.0013 \\
\hline 22 & 0.0154 & 0.0141 & 0.0095 & 0.0047 & 0.0043 & 0.0083 & 0.0020 \\
\hline 23 & 0.0077 & 0.0117 & 0.0062 & 0.0041 & 0.0025 & 0.0012 & 0.0006 \\
\hline 24 & 0.0000 & 0.0000 & 0.0000 & 0.0000 & 0.0000 & 0.0000 & 0.0000 \\
\hline \multicolumn{8}{|c|}{ Mol fraction of the sum of isomers in the group in the gaseous product } \\
\hline 1 & & 0.1017 & 0.1030 & 0.1149 & 0.2221 & 0.1875 & 0.1033 \\
\hline 2 & & 0.2295 & 0.2208 & 0.2300 & 0.4299 & 0.4135 & 0.4092 \\
\hline 3 & & 0.3420 & 0.3305 & 0.3189 & 0.0118 & 0.0794 & 0.1381 \\
\hline 4 & & 0.1893 & 0.1965 & 0.1947 & 0.1347 & 0.2166 & 0.1577 \\
\hline 5 & & 0.0831 & 0.0898 & 0.0906 & 0.1161 & 0.1593 & 0.1443 \\
\hline 6 & & 0.0432 & 0.0483 & 0.0446 & 0.0682 & 0.0959 & 0.0475 \\
\hline 7 & & 0.0104 & 0.0109 & 0.0063 & 0.0066 & 0.0142 & 0.0000 \\
\hline 8 & & 0.0007 & 0.0003 & 0.0000 & 0.0102 & 0.0297 & 0.0000 \\
\hline
\end{tabular}

efficiency of industrial metabolism and decrease the impact on the environment if exergy content in products or waste (which presumably encapsulates primary energy) is recycled. This can be achieved in several ways. For instance, different types of recycling can be employed. Therefore, exergy analysis is useful for assessing the true energy efficiency of different industrial processes, including the conversion of waste to fuels or energy.

Based on the results obtained in laboratory reactor, a pilot installation was proposed for the process in which $200 \mathrm{~kg} / \mathrm{h}$ of real mixture of polyethylene and propylene (ratio PE:PP = 3:1) waste may be utilized using thermal degradation in molten metal. The scheme of the installation is presented in Fig. 4.

Assessment and calculation of exergy efficiency of the simulated process were based on the following assumptions:

1. There is no mechanical disintegration of waste, as no additional energy is needed.

2. Only chemical and physical exergy are considered in this paper.

3. The reference state is described by following parameters: $T=298.15 \mathrm{~K}$ and $P=0.101325 \mathrm{MPa}$.

4. Calculations of physical exergy are based on standard values of enthalpy and entropy [19, 20]. 
(a)
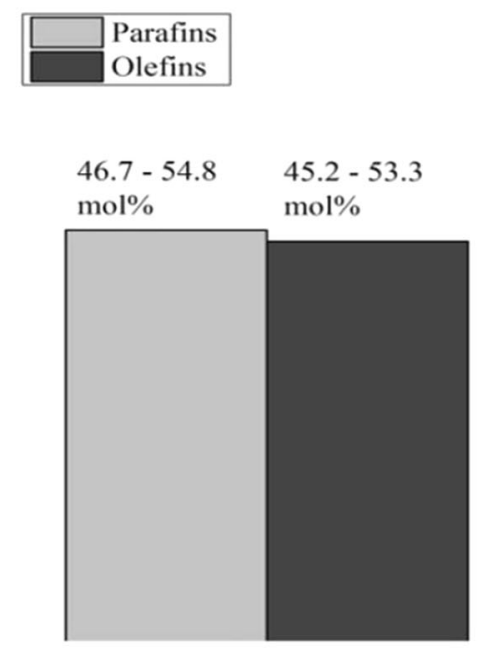

PE

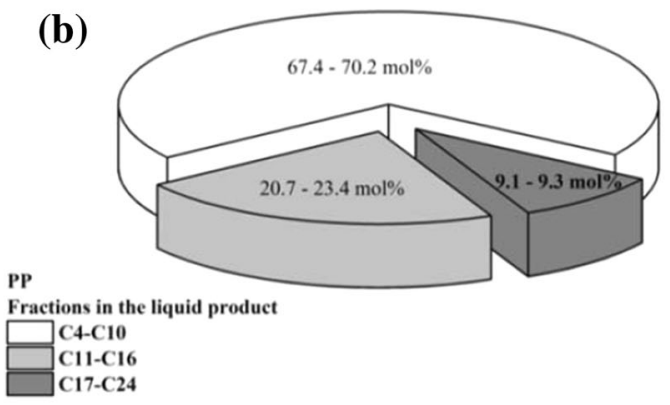

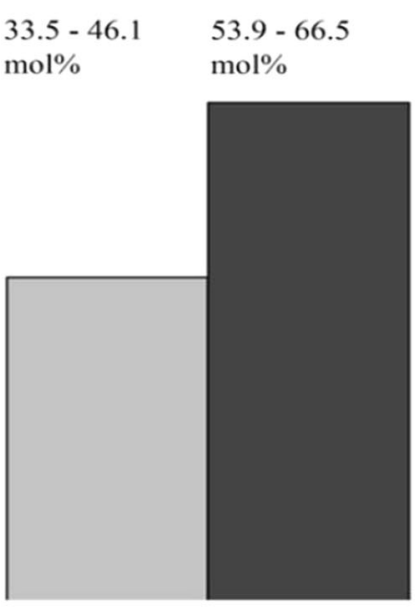

PP

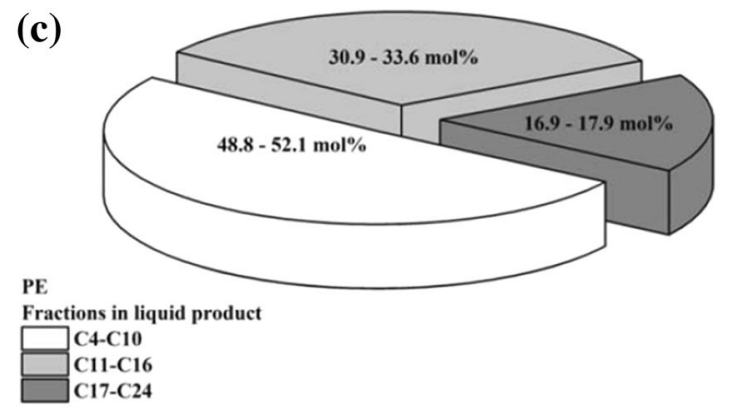

Fig. 2 Fractional composition of liquid products; a the content of olefins and paraffin in the product obtained from PE and PP; $\mathbf{b}$, $\mathbf{c}$ the fraction of light hydrocarbons, heavy hydrocarbons and light waxes in the product obtained from polypropylene $(P P)$ and polyethylene $(P E)$

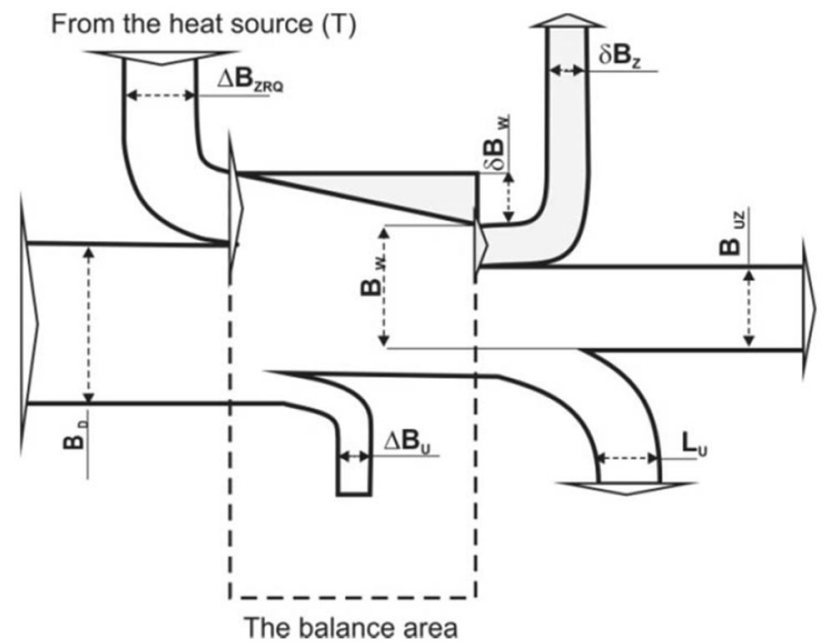

Fig. 3 Exergy balancing for the flow system

5. Chemical exergy of the sawdust, waste and coke is calculated using higher heating value of the components.

6. Mineral impurities consist of $\mathrm{SiO}_{2}$.
7. Electric energy exergy equals energy power.

8. Exergy of $\mathrm{SO}_{2}, \mathrm{NO}_{x}$, construction materials, labor and capital is not considered.

9. It is assumed that process is carried out continuously.

10. The values of specific chemical exergy of the components are presented in Table 3.

11. Exergy of the stream " $j$ " $B_{j}$ is expressed as:

$B_{j}=\sum_{i=1}^{N} F_{i} \times b_{i}$

where $b_{i}$, denotes specific exergy of the component " $i$ " (kJ/ $\mathrm{kg}$ ); $F_{i}$, mass stream of the component in the " $j$ " stream $(\mathrm{kg} / \mathrm{h})$; and $N$, number of components.

12. Hot flue gases from gasification of the biomass are the basic source of the heat demanded to degrade plastic waste. It is assumed that sawdust $(112 \mathrm{~kg} / \mathrm{h}$; $11.7 \mathrm{~kJ} / \mathrm{kg}$ ) is gasified in the gasifier and combusted to carry out the process.

13. Combustion of recycled gas product is a supplementary source of energy. Water is required for cooling of the liquid product and to the scrubber for purifying flue gases.

14. Electric power is also needed: for the waste and sawdust feeders, fans, water and product pumps, 


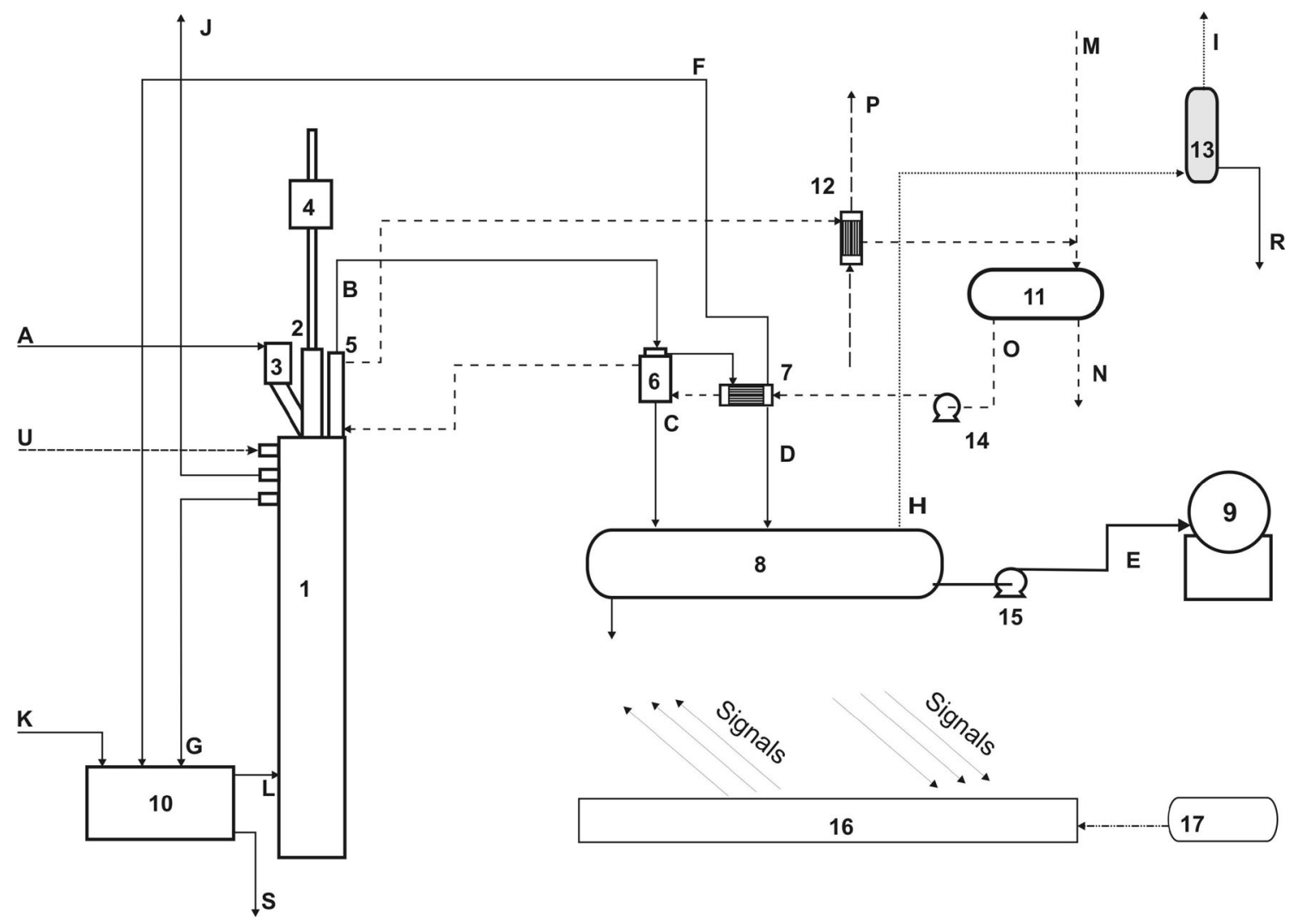

Fig. 4 Pilot installation scheme for the thermal degradation of waste polyolefins in a vertical tubular reactor with molten metal. 1 Reactor with a heating jacket; 2 inner tube of the reactor; 3 and 4 feeder with a screw conveyor and the driver; 5, 6, 7 coolers; 8 liquid fuel receiver;

Table 3 Specific chemical exergy of the components

\begin{tabular}{llc}
\hline & Component & $\begin{array}{l}\text { Specific chemical exergy } \\
b_{\text {chi }}(\mathrm{kJ} / \mathrm{kg})\end{array}$ \\
\hline 1 & Polyethylene $\left(\mathrm{PE}_{(\mathrm{S})}\right)$ & 48360.00 \\
2 & Polypropylene $(\mathrm{PP})$ & 47850.00 \\
3 & Silica $\left(\mathrm{SiO}_{2(\mathrm{~S})}\right)$ & 36.61 \\
4 & Coke (organic tar $\left.{ }_{(\mathrm{s})}\right)$ & 39639.72 \\
5 & Biomass (dry sawdust $\left.\mathrm{ds}_{(\mathrm{s})}\right)$ & 12704.00 \\
6 & Gasoline fraction $\left[\left(\mathrm{C}_{4}-\mathrm{C}_{10}\right)_{(\mathrm{L})}\right]$ & 48147.01 \\
7 & Diesel fraction $\left[\left(\mathrm{C}_{11}-\mathrm{C}_{16}\right)_{(\mathrm{L})}\right]$ & 48201.46 \\
8 & Light waxes fraction $\left[\left(\mathrm{C}_{17}-\mathrm{C}_{24}\right)_{(\mathrm{L})}\right]$ & 47686.29 \\
9 & Water $\left(\mathrm{H}_{2} \mathrm{O}_{(\mathrm{L})}\right)$ & 49.96 \\
10 & Water $\left(\mathrm{H}_{2} \mathrm{O}_{(\mathrm{G})}\right)$ & 527.34 \\
11 & Carbon dioxide $\left(\mathrm{CO}_{2(\mathrm{G})}\right)$ & 442.63 \\
12 & Nitrogen $\left(\mathrm{N}_{2(\mathrm{G})}\right)$ & 25.70 \\
13 & Oxygen $\left(\mathrm{O}_{2(\mathrm{~g})}\right)$ & 24.63 \\
\hline
\end{tabular}

control and acquisition data systems and the lighting system.

15. The average reaction rate in the pilot plant is assumed to be $3000 \mathrm{~kg} / \mathrm{m}^{3} \mathrm{~h}$.
9 liquid fuel tank; 10 biomass gasifier (i.e., sawdust); 11 storage reservoir for cooling water; 12 heat exchanger/water cooler; 13 scrubber for gas purification; 14 water pump; 15 liquid product pump; and 16,17 control and acquisition data system

16. It is assumed that synergistic effects of mixing PE and PP do not occur in cracking in the reactor.

\section{Results and discussion}

Based on the above assumptions, we calculated mass balance and the values of exergy streams for the proposed pilot installation. The idea of the balance is shown in Fig. 5 and the results of mass balance calculations and exergy streams calculations are presented in Table 4.

Exergy efficiency in this process is equal to $79.5 \%$ if the mixture of liquid hydrocarbons is the final product. However, it seems that a better option involves using the obtained total product of degradation (without condensation) to generate electricity instead of processing waste. This leads to the increase in demand for biomass (by about $20 \%$ ) but, on the other hand, it decreases demand for electricity and cooling water, Moreover, exhaust gases can also be used to produce hot water for the heating system. That, in turn, allows an increase in exergy efficiency by about $2 \%$. In addition, generation of electricity (energy of 


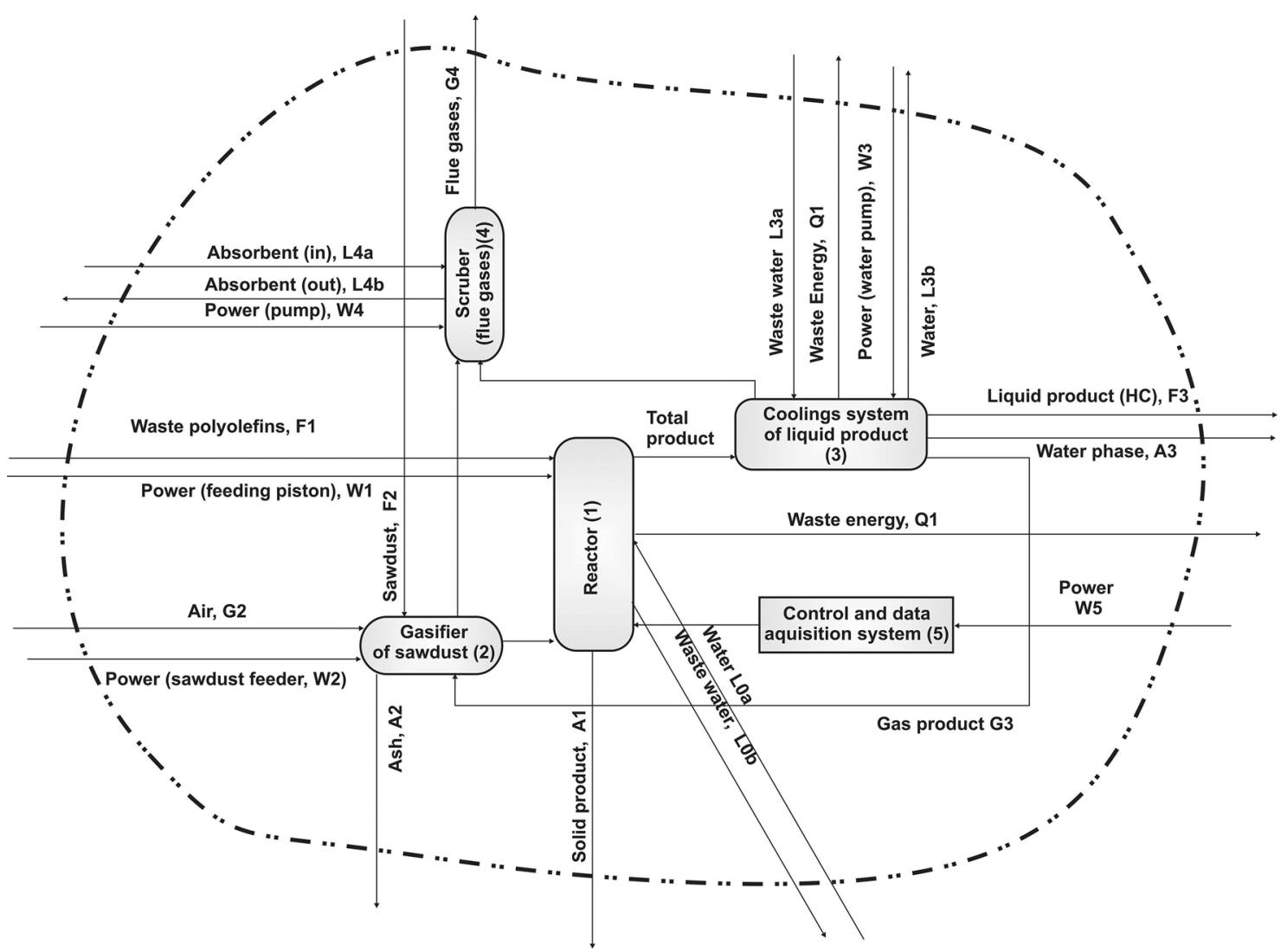

Fig. 5 Exergy streams and mass balance of the pilot installation

Table 4 The profile of balance streams for the installation and exergy streams

\begin{tabular}{|c|c|c|c|c|c|c|c|c|c|c|c|c|}
\hline & 1 & 2 & 3 & 4 & 5 & 6 & 7 & 8 & 9 & 10 & 11 & 12 \\
\hline Stream symbol & $\mathrm{F} 1$ & $\mathrm{~F} 2$ & G2 & $\sum L_{\mathrm{a}}$ & F3 & $\mathrm{A} 1$ & $\mathrm{~A} 2$ & $\mathrm{~A} 3$ & G4 & $\sum L_{\mathrm{b}}$ & $\sum W$ & $\sum Q_{1}$ \\
\hline Exergy balance & $B_{\mathrm{I} 1}$ & $B_{\mathrm{I} 2}$ & $B_{\mathrm{I} 3}$ & $B_{\mathrm{I} 4}$ & $\mathrm{~B}_{\mathrm{O} 1}$ & $B_{\mathrm{O} 2}$ & $B_{\mathrm{O} 3}$ & $B_{\mathrm{O} 4}$ & $B_{\mathrm{O} 5}$ & $B_{\mathrm{O} 6}$ & $B_{\mathrm{I} 5}$ & $B_{\mathrm{O} 7}$ \\
\hline Temperature $(\mathrm{K})$ & 283 & 283 & 283 & 283 & 298 & 673 & 673 & 298 & 423 & 293 & - & - \\
\hline Pressure (MPa) & 0.1 & 0.1 & 0.1 & 0.3 & 0.1 & 0.1 & 0.1 & 0.1 & 0.1 & - & - & - \\
\hline Mass flow (kg/h) & 200 & 135 & 1042 & 86.8 & 180.4 & 5.16 & 0.72 & 3.6 & 1165.2 & 86.8 & & \\
\hline \multicolumn{13}{|l|}{ Composition (\% mass) } \\
\hline PP & 24.1 & & & & & & & & & & & \\
\hline PE & 72.7 & & & & & & & & & & & \\
\hline $\mathrm{H}_{2} \mathrm{O}_{(\mathrm{L})}$ & 1.4 & 16.0 & & 100 & & & & $\sim 100$ & & $\sim 100$ & & \\
\hline $\mathrm{C}_{4}-\mathrm{C}_{10(\mathrm{~L})}$ & & & & & 41.7 & & & & & & & \\
\hline $\mathrm{C}_{11}-\mathrm{C}_{16(\mathrm{~L})}$ & & & & & 33.0 & & & & & & & \\
\hline $\mathrm{C}_{17}-\mathrm{C}_{24(\mathrm{~L})}$ & & & & & 25.3 & & & & & & & \\
\hline $\mathrm{CO}_{2(\mathrm{G})}$ & & & & & & & & & 18.1 & & & \\
\hline $\mathrm{H}_{2} \mathrm{O}_{(\mathrm{G})}$ & & & & & & & & & 8.1 & & & \\
\hline $\mathrm{N}_{2(\mathrm{G})}$ & & & 77.0 & & & & & & 68.7 & & & \\
\hline $\mathrm{O}_{2(\mathrm{G})}$ & & & 23.0 & & & & & & 5.1 & & & \\
\hline $\mathrm{SiO}_{2}$ & 1.8 & & & & & 70 & 100 & & & & & \\
\hline Coke & & & & & & 30 & & & & & & \\
\hline Sawdust & & 84.0 & & & & & & & & & & \\
\hline Exergy stream (MJ/h) & 9341.5 & 1441.7 & 26.5 & 4.34 & 8667.9 & 61.5 & 0.03 & 0.18 & 198.0 & 4.34 & 252.8 & 2064.9 \\
\hline
\end{tabular}


higher quality) at the site allows avoiding the cost involved in transporting the product to the refinery or to a chemical plant. True exergy efficiency will be probably not so high. In real industrial processes thermal losses may be higher. Furthermore, it should be noted that in the paper we conducted only a simple exergy analysis. Applying more advanced methods, such as extended exergy analysis or emergy analysis and considering the exergy of construction materials (i.e., steel, lead, tin etc.), labor and capital, can demonstrate that the real efficiency is lower. However, exergy (and energy) efficiency of every feedstock recycling process should be higher than the efficiency of combustion, which typically ranges from 25 to $35 \%$ for this type of waste.

\section{Conclusions}

At present, various options are available to utilize plastic waste and recover primary energy and/or raw materials used to produce polymers. Depending on local conditions, each specific situation requires the selection of the best technology that takes account of several implications (environmental, social, economic, legal and technical). The best way to assess and compare different technologies of waste utilization is thermodynamic (that is, exergy) analysis because it considers many of these implications.

The application of exergy analysis to estimate the usefulness and efficiency of the processes is an effective method in evaluation and screening alternative technologies for sustainable development. This allows us to identify targets for direct or indirect waste recycling with respect of a single industrial process and the total waste management system at the national level. This method complements also the assessment of environmental impact of products made of plastics that is conducted using the LCA.

Thermal decomposition of PE or PP in a molten metal bed is a promising method compared to catalytic cracking carried out in different types of reactors. Over $90 \%$ of waste polyolefins may be converted into a liquid producta mixture of hydrocarbons $\left(\mathrm{C}_{4}-\mathrm{C}_{24}\right)$.

Exergy efficiency of the process is high, which means thermal degradation in molten alloy (of tin and lead) is a more valuable technology than the incineration of waste plastics. Incineration produces high levels of an entropy stream to the environment and requires a great deal of attention.

Open Access This article is distributed under the terms of the Creative Commons Attribution License which permits any use, distribution, and reproduction in any medium, provided the original author(s) and the source are credited.

\section{References}

1. Kaminsky W (2011) Feedstock recycling of nitrogen containing polymers by fluidized bed pyrolysis. In: Paper presented at the 6th international symposium on feedstock recycling of polymeric materials, Toledo, 5-7 October 2011

2. Williams PT (2011) Thermal and pyrolytic processes for the valorization of waste plastics. In: Paper presented at the 6th international symposium on feedstock recycling of polymeric materials, Toledo, 5-7 October 2011

3. GUS (2008) Statistical yearbook of the Republic of Poland (2208). GUS, Warsaw

4. Aguado J, Serrano DP, Escola MJ (2008) Fuels from waste plastics by thermal and catalytic processes. A review. Ind Eng Chem Res 47(21):7982-7992

5. Walendziewski J (2005) Continuous flow cracking of waste plastics. Fuel Process Technol 86(12-13):1265-1278

6. Scheirs J, Kaminski W (eds) (2006) Feedstock recycling and pyrolysis of waste plastics: converting waste plastics into diesel and other fuels. Wiley Series in Polymer Sciences, John Wiley, New York

7. Alchemix (2003) Executive summary: private information from Alchemix Corporation and website. http://www.alchemix.net

8. Hsu PC, Foster KG, Ford TD, Wallman PH, Watkins BE, Pruneda CO, Adamson MG (2000) Treatment of solid wastes with molten salt oxidation. Waste Manag 20(5-6):363-368

9. Newborough M, Highgate P, Vaughan P (2002) Thermal depolymerisation of scrap polymers. Appl Therm Eng 22(17): 1875-1883

10. Stelmachowski M (2008) The reactor and method for thermal conversion of waste polymers. Patent (P384806), Poland

11. Stelmachowski M (2010) Thermal conversion of waste polyolefins to the mixture of hydrocarbons in the reactor with molten metal bed. Energy Convers Manag 51:2016-2024

12. Stelmachowski M (2010) Conversion of waste rubber to the mixture of hydrocarbons in the reactor with molten metal. Energy Convers Manag 50:1739-1745

13. Domingo J, Cabanero D (1949) Process and device for regeneration of monomer from polymethyl methacrylate. Spanish patent (192909), Spain

14. Mausre WE, Donahue JR, Larue GW, Bonney LH, Glanton GW, Harris WL (1989) Method and apparatus for thermal conversion of organic matter. US Patent (342056), USA

15. Wall G, Gong M (2001) On exergy and sustainable development-part 1: conditions and concepts. Exergy Int J 1(3):28-145; part 2: indicators and methods. Exergy Int J 1(4):217-233

16. Dewulf JP, van Langenhov H (2002) Quantitate assessment of solid waste treatment systems in the industrial ecology perspective by exergy analysis. Env Sci Technol 36:1130-1135

17. Szargut J (2005) Exergy analysis: technical and ecological applications. WIT press, Southampton

18. Sciubba E (2003) Extended exergy accounting applied to energy recovery from waste: the concept of total recycling. Energy 28:1315-1334

19. Gurvich LV, Veyts IV, Alcock CB (eds) (1989) Thermodynamic properties of individual substances, 4th edn. Hemisphere Publishing Corporation, New York

20. Chase MW, Davies CA, Downey JR, Frurip DJ, McDonald RA, Syverud AN (1985) JANAF thermochemical tables, third edn. J Phys Chem Ref Data 14(Suppl 1) 